\section{Sleep quality among industrial workers: related factors and impact}

Sleep quality among industrial workers

\author{
Wanpen Songkham, Jirawan Deeluea, Benjamas Suksatit and \\ Jindarat Chaiard \\ Faculty of Nursing, Chiang Mai University, Chiang Mai, Thailand
}

\begin{abstract}
Purpose - The purpose of this paper is to explore the prevalence and determinants of poor sleep quality among industrial workers in Thailand. Additionally, the authors assess the risk of work-related injuries associated with poor sleep quality.

Design/methodology/approach - A descriptive correlational research was implemented. A total of 472 workers from the northern region of Thailand contributed to this study. Sleep quality was assessed by the Thai version of the Pittsburgh Sleep Quality Index (Thai-PSQI). The score of more than five indicated poor sleep quality. Participants completed self-administered demographic, work characteristics and work-related injury questionnaires. Data were analyzed by applying descriptive and logistic regression statistical techniques.

Findings - More than one-third of the workers had reported poor sleep quality. Results from multivariable logistic regression analysis yielded male gender $(\mathrm{OR}=2.74,95 \% \mathrm{CI} 1.46-5.17)$, alcohol drinking $(\mathrm{OR}=2.1$, $95 \%$ CI 1.24-3.35), pain (OR $=2.05,95 \%$ CI $1.32-3.17)$ and rotating shift work (OR $=1.94,95 \%$ CI $1.23-3.05)$ increased the risk of poor sleep quality. Furthermore, poor sleep quality was statistically significantly associated with the risk of work-related injuries $(\mathrm{OR}=3.98,95 \% \mathrm{CI}=2.39-6.66)$.

Originality/value - Findings of this study indicate that the prevalence of poor sleep quality is high among industrial workers. Work characteristics and health behaviors were associated with poor sleep quality which increases the risk of work-related injuries. Modification of work environment and personal life style choices can improve quality of sleep among workers and consequently lower incidence of workrelated injuries.
\end{abstract}

Keywords Sleep quality, Industrial worker

Paper type Research paper

\section{Introduction}

Sleep quality is the tenet of good health and economic productivity. Poor sleep quality increases the rate of accidents, work-related errors and absenteeism and reduces overall work performance. Additionally, poor sleep quality is associated with the decline of personal relationships and increases the overall rate of premature mortality[1-7].

Sleep quality is influenced by an array of factors ranging from demographic characteristics, to personal life style choices to type of work and condition of work environment[8]. Advanced age, unmarried status, smoking habit and alcohol consumption have been reported to compromise quality of sleep[8-11]. Among the workforce, work-related physical fatigue and rotating shift work and personal coping capacity have been reported to influence the quality of sleep [9,11-13].

(C) Wanpen Songkham, Jirawan Deeluea, Benjamas Suksatit and Jindarat Chaiard. Published in Journal of Health Research. Published by Emerald Publishing Limited. This article is published under the Creative Commons Attribution (CC BY 4.0) licence. Anyone may reproduce, distribute, translate and create derivative works of this article (for both commercial \& non-commercial purposes), subject to full attribution to the original publication and authors. The full terms of this licence may be seen at http://creativecommons. org/licences/by/4.0/legalcode

This study was supported by Chiang Mai University Research Fund. Special thank to Dr Azadeh Stark for editing this manuscript.
Received 13 August 2018 Revised 23 August 2018 Accepted 29 August 2018 
JHR

33,2

Sleep disturbances, in the longer term, affect the safety and health of workers. Sleep problems such as obstructive sleep apnea, excessive daytime sleepiness, and sleep debts are associated to accidents or near-miss accidents[14]. In addition, the National Health Interview Survey revealed that short sleep duration (less than $6 \mathrm{~h}$ ) increased risk of injuries[15]. A study of cases admitted to hospital due to a moderate to severe work injury indicated that poor sleep quality which resulted from short sleep duration or long duration of working was related to work injury of any type[16].

In Thailand, research on sleep quality, primarily, has been focused on hospitalized patients and hospital staff, i.e. nurses[17-21]. There is a paucity of such research among industrial workers in Thailand. Our review of medical and scientific literature yielded only two studies on sleep quality among Thai industrial workers [5, 22]. We conducted a study with the objective of assessing the prevalence of and risk factors for poor quality of sleep and its impact on work-related injuries.

\section{Materials and methods}

\section{Study design and sample size}

A descriptive correlational research was implemented. Study participants consisted of employees working in three large factories in the northern region, Thailand. Sample size was calculated based on findings by Chol et al.[8]. Similarly, we included 14 variables in our sample size calculation, using $G^{*}$ Power statistical package. Our calculation yielded a sample size of 393 with the statistical power of 80 percent at 0.05 statistical significance. Finally, we inflated the sample size by 20 percent $(n=475)$ to allow for drop outs and/or incomplete questionnaires.

\section{Research ethics}

The research study was approved by the Research Ethic Committee of the Faculty of Nursing, Chiang Mai University (ref: no. 145/2015). Participants signed informed consents and confidentiality of their information was protected.

\section{Data collection}

Large factories in the Northern region of Thailand were contacted and asked permission for data collection. Three factories agreed to participate in the survey. A self-reported questionnaire was distributed to industrial workers who met the inclusion criteria: aged 18 years and older; able to read in the Thai language; full-time working and having experience on working at industrial setting at least one month.

We designed a self-administered questionnaire to collect information about demographic and life style characteristics, quality of sleep and work-related injuries. Participants were asked to provide information about their age at the time of participation in the study, gender, marital status, education level, smoking and alcohol consumption habits, exercise, pain, body weight and height, year of working experience, job satisfaction and shift work.

Sleep quality was measured by the Thai version of the Pittsburgh Sleep Quality Index (Thai-PSQI). Information about the Thai-PSQI has been published previously[23]. It is a standardized self-reported questionnaire that measures the overall sleep quality over a period of one month. Thai-PSQI contains 19 self-rated questions grouped into seven categories: sleep duration, sleep disturbances, sleep latency, daytime dysfunction, habitual sleep efficiency, subjective sleep quality and use of sleep medications. Each component is scored from 0 to 3, yielding a global PSQI score between 0 and 21. A score more than five categorizes quality of sleep as poor[24].

We developed work-related injury questionnaire to assess the injury experiences during the year before the survey. Responses were dichotomized into "Yes" or "No." The Thai-PSQI questionnaire was piloted among the workers. The reliability of our instrument was assessed by using Cronbach's $\alpha$ statistics $(\alpha=0.85)$. 


\section{Statistical analysis}

Descriptive statistics were used to summarize demographic, sleep quality and work-related injuries. The variable age at the time of participation in the study was dichotomized into younger than age 45 and age 45 or older. Participants were classified based on their education level into "Less than College" or "At Least 4-Year of College." For the variable years of work experience, we opted to classify the study participants into two groups, "Less than or equal 5-Year of Work Experience" and "More than 5-Year of Work Experience." Body mass index (BMI) was calculated using the formula: weight (kg)/[height $(\mathrm{m})]^{2}$ and was dichotomized as $18.5 \leqslant \mathrm{BMI} \leqslant 22.9$ or normal and BMI $\geqslant 23$ or overweight. For the remaining variables, participants were classified into either "Yes" or "No" group, based on their responses.

We applied logistic regression statistics to estimate the risk of poor sleep quality or work-related injuries. In developing the best-fitted model, we first estimated the individual effect of each variable on the outcome, poor sleep quality. Univariate logistic regression analysis was used for association between poor sleep quality and work-related injuries. Variables with a $p$-value of $<0.2$ were considered as candidate variables. The final model contained only variables with $p$-value $\leqslant 0.05$. All statistical tests were two-sided and analyses were performed using the licensed SPSS version 13.

\section{Results}

A total of 472 (99.4 percent) participants completed and returned the questionnaires. The majority of the participants were male ( 69.3 percent, $n=327$ ). In total, 82 percent of the participants were married and 66.3 percent $(n=313)$ had less than college education. Among the participants, 21.2 percent $(n=100)$ were smokers and 61.9 percent $(n=292)$ consumed alcohol. Regular physical activities was reported by 69.3 percent $(n=327)$ of the participants and 41.9 percent $(n=198)$ had reported experiencing chronic pain. About one-third (35 percent, $n=175$ ) of the study participants were classified as overweight. The majority (88.3 percent, $n=417$ ) had more than five years of work experience, with 40 percent $(n=189)$ in rotating shift work schedule. Finally, 70.3 percent $(n=332)$ had reported satisfaction with their jobs (Table I).

Poor sleep quality was reported by 33.7 percent $(n=159)$. Participants whose Thai-PSQI scores had categorized into the good sleep quality category were predominantly men (39.6 percent, $n=187$ ), age 45 or older (44.1 percent, $n=208$ ), married (55.9 percent, $n=264$ ) non-smokers (56.3 percent, $n=266$ ) and had reported of no pain (42.2 percent, $n=199)$. The proportions of participants who had reported of consuming alcohol (33.7 percent, $n=159$ ) and those who had reported otherwise (32.6 percent, $n=154$ ) was almost equal. Participants who had reported more than five years of work experience ( 61.0 percent, $n=288$ ) constituted the majority in the category of Good Sleep Quality. Finally, participants whose work schedule was classified as non-shift represented 46 percent $(n=217)$ of the good sleep quality group (Table II).

Results from the multivariable logistic regression analysis are presented in Table III. Male gender $(\mathrm{OR}=2.74,95$ percent $\mathrm{CI} 1.46-5.17)$, alcohol consumption $(\mathrm{OR}=2.1,95 \% \mathrm{CI}$ $1.24-3.35)$, pain $(\mathrm{OR}=2.05,95 \%$ CI $1.32-3.17)$, and rotating shift work $(\mathrm{OR}=1.94,95 \%$ CI 1.23-3.05) were associated with poor sleep quality.

Our statistical analysis yielded poor sleep quality was statistically significantly associated with work-related injuries $(p<0.001)$. Workers with poor sleep quality had about 3.98 times higher risk of work-related injuries than their counterparts with good sleep quality $(\mathrm{OR}=3.98,95 \% \mathrm{CI}=2.39-6.66)$.

\section{Discussion}

Findings from this study suggest that the prevalence of poor sleep quality is as high as 33.7 percent among Thai industrail workforce. Analyses of data yielded that male workers were
Sleep quality among industrial workers 


\begin{tabular}{|c|c|c|}
\hline & Frequency & Percent \\
\hline $\begin{array}{l}\text { Gender } \\
\text { Male } \\
\text { Female }\end{array}$ & $\begin{array}{l}327 \\
145\end{array}$ & $\begin{array}{l}69.3 \\
30.7\end{array}$ \\
\hline $\begin{array}{l}\text { Age (years) } \\
<45 \\
\geqslant 45\end{array}$ & $\begin{array}{l}176 \\
296\end{array}$ & $\begin{array}{l}37.3 \\
62.7\end{array}$ \\
\hline $\begin{array}{l}\text { Marital status } \\
\text { Married } \\
\text { Single }\end{array}$ & $\begin{array}{r}384 \\
88\end{array}$ & $\begin{array}{l}81.4 \\
18.6\end{array}$ \\
\hline $\begin{array}{l}\text { Education } \\
<\text { College } \\
4 \text {-year college or higher }\end{array}$ & $\begin{array}{l}313 \\
159\end{array}$ & $\begin{array}{l}66.3 \\
33.7\end{array}$ \\
\hline $\begin{array}{l}\text { Smoking habit } \\
\text { Smokers } \\
\text { Non-smokers }\end{array}$ & $\begin{array}{l}100 \\
372\end{array}$ & $\begin{array}{l}21.2 \\
78.8\end{array}$ \\
\hline $\begin{array}{l}\text { Alcohol consumption } \\
\text { Yes } \\
\text { No }\end{array}$ & $\begin{array}{l}292 \\
180\end{array}$ & $\begin{array}{l}61.9 \\
38.1\end{array}$ \\
\hline $\begin{array}{l}\text { Exercise } \\
\text { Yes } \\
\text { No }\end{array}$ & $\begin{array}{l}327 \\
145\end{array}$ & $\begin{array}{l}69.3 \\
30.7\end{array}$ \\
\hline $\begin{array}{l}\text { Chronic pain } \\
\text { Yes } \\
\text { No }\end{array}$ & $\begin{array}{l}198 \\
274\end{array}$ & $\begin{array}{l}41.9 \\
58.1\end{array}$ \\
\hline $\begin{array}{l}\text { BMI } \\
\text { Normal }\left(18.5-22.9 \mathrm{~kg} / \mathrm{m}^{2}\right) \\
\text { Overweight }\left(\geqslant 23 \mathrm{~kg} / \mathrm{m}^{2}\right)\end{array}$ & $\begin{array}{l}297 \\
175\end{array}$ & $\begin{array}{l}62.9 \\
37.1\end{array}$ \\
\hline $\begin{array}{l}\text { Year of work experience } \\
\leqslant 5 \\
>5\end{array}$ & $\begin{array}{r}55 \\
417\end{array}$ & $\begin{array}{l}11.7 \\
88.3\end{array}$ \\
\hline $\begin{array}{l}\text { Shift work } \\
\text { Yes } \\
\text { No }\end{array}$ & $\begin{array}{l}189 \\
283\end{array}$ & $\begin{array}{l}40.0 \\
60.0\end{array}$ \\
\hline $\begin{array}{l}\text { Job satisfaction } \\
\text { Yes } \\
\text { No } \\
\text { Notes: } n=472\end{array}$ & $\begin{array}{l}332 \\
140\end{array}$ & $\begin{array}{l}70.3 \\
29.7\end{array}$ \\
\hline
\end{tabular}

at more than two-fold risk for poor sleep quality. Our findings contradict previous studies which had reported females were more likely to experience poor quality sleep. The authors had attributed the poor quality of sleep among women to female reproductive hormonal changes $[3,25]$. The difference between our study and previous ones might be explained by the differences in life style behaviors and age of participants. In our study the majority of the participants were 45 years of age and older. Additionally, the majority of participants in our study were non-smokers and were physically active and within the recommended range for their ideal body weights[26]. 


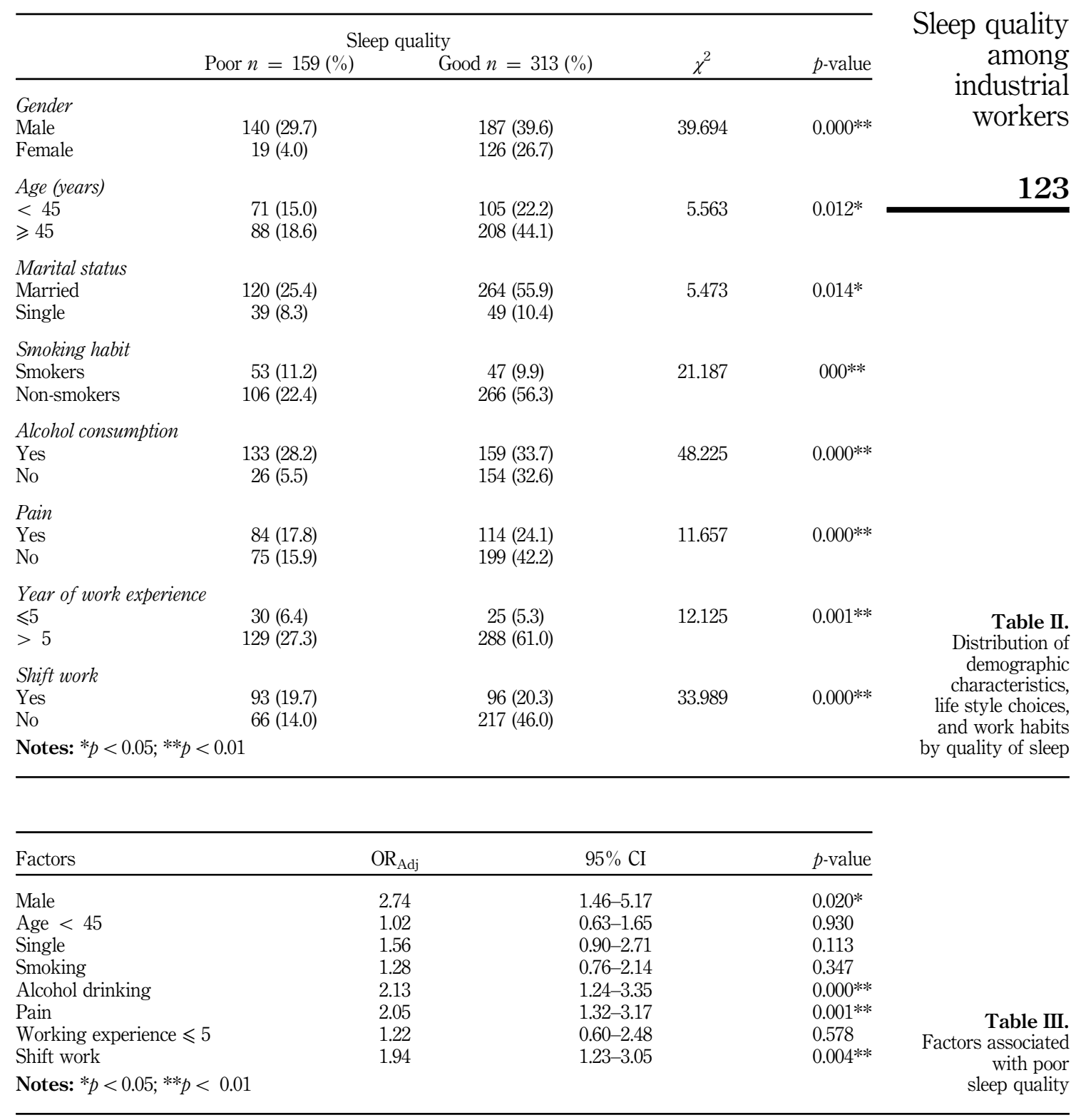

Our findings that alcohol consumption increases the risk of poor sleep quality concur with previous reports[8]. In this study, we did not assess quantity of alcohol consumed per day; however, others have reported sleep quality is compromised with increased alcohol consumption[27]. Our results suggested of an association between smoking and poor sleep quality, although this association did not reach the level of statistical significance. Previous studies suggest that smoking habit compromises sleep quality because of its adverse impact on the respiratory system[28, 29]. For example, Krishnan et al.[30] argues that smoking 
JHR

33,2

124

induces collapse of the upper airway muscles; furthermore, they suggest that nicotine changes neural reflexes which increase in arousal threshold from sleep. Additionally, the authors propose that smoking induces inflammation of the upper airways.

Insufficient sleep duration and quality are commonly reported in patients suffering from a variety of acute or chronic pain conditions[31, 32]. In this study, industrial workers who had pain experienced from musculoskeletal disorders such as shoulder pain, low back pain or knee pain reported poorer sleep than those who had not. Pain perception was significantly associated with poor sleep quality. However, across most prior medical interventions, the development of pain as a side effect coincides with the development of sleep disturbance and vice versa[33]. Recent experimental studies suggested that sleep disturbances may impair key processes that contribute to the development and maintenance of chronic pain[34].

Workers who had working experience less than five years reported high poor sleep. It can be described by their age. As young adults, sleep quality may be involved with their social-techno life style and ability to cope with the stress[10].

Regarding shift work, industrial workers who had previous shift work experiences were more likely to have poor sleep quality than those who had never done shift work. Nevertheless, individual tolerance to shift work remains a multifaceted problem that is affected by the number of consecutive work hours and shifts, the rest periods and the predictability of work schedules[35]. In this study, workers in industrial setting work for 8-h shift. However, the schedule can be arranged as 16 consecutive work hours (day shift to evening shift) depending on workload and their work tasks. Most of workers had one-hour rest period between day and evening shift. We also found that only male workers had shift work. Therefore, it might be an explanation why male workers in this study reported poorer sleep quality than female workers.

Our findings also indicated that poor sleep quality was significantly associated with work-related injury, workers with poor sleep quality had a 3.98 times higher risk of being injured than workers with good sleep quality $(\mathrm{OR}=3.98,95$ percent $\mathrm{CI}=2.39-6.66)$. The result was consistent with a systematic review and meta-analysis of sleep problems and work injuries by Uehli et al.[2]. In that study, it was found that workers with sleep problems had 1.62 times higher risk of being injured than workers without sleep problems $(\mathrm{RR}=$ 1.62, 95 percent CI: $1.43-1.84)$.

The strength of this study was the large samples size and high response rate. There are some limitations in this study. First, since this was a cross-sectional design, the findings from this study cannot determine causal relationships as might a prospective study. Second, the results were also based on the data from a convenience sample of large factories in Northern Thailand, thus the results may not be generalizable to all working population. Third, all of the survey data were based on self-report without clinical verification, which may bias the results. As a result, this study was not able to determine which aspects of the internet or social media use (e.g. Facebook, Line, Twitter and Youtube) which potentially related to poor sleep quality. Forth, other factors that possibly affect sleep quality, such as stress, anxiety, medication, drug use and sleep hygiene were not measured.

\section{Conclusions and recommendation}

Industrial workers with health risk behavior profiles, being male and shift work were risk for having poor sleep quality. Low sleep quality was associated with an increased risk of occupation injury. Health-related professional should pay attention to these factors which increase the workers' vulnerability to poor sleep quality. Based on study results, developing of health education regarding good sleep hygiene, healthy behaviors and improvement of working conditions should be implemented for industrial workers. 


\section{References}

1. Kling RN, Mcleod CB, Koehoom M. Sleep problems and workplace injuries in Canada. Sleep. 2010; 33(5): 611-18.

2. Uehli K, Mehta AJ, Miedinger D, Hug K, Schindler C, Holsboer-Trachsler E, et al. Sleep problems and work injuries: a systematic review and meta analysis. Sleep Med Rev. 2014; 18(1): 61-73.

3. Metlaine A. Socioeconomic impact of insomnia in working populations. Ind Health. 2005; 43(1): 11-19.

4. Vgontzas AN, Liao D, Pejovic S, Calhoun S, Karataraki M, Basta M, et al. Insomnia with short sleep duration and mortality: the Penn state cohort. Sleep. 2010; 33(9): 1159-64.

5. Phatrabuddha N, Yingratanasuk T, Rotwannasin P, Jaidee W, Krajaiklang, N. Assessment of sleep deprivation and fatigue among chemical transportation drivers in Chonburi, Thailand. Saf Health Work. 2018; 9(2): 159-63.

6. Rosekind MR., Gregory KB, Mallis MM, Brandt SL, Seal B, Lerner D. The cost of poor sleep: workplace productivity loss and associated costs. J Occup Environ Med. 2010; 52(1): 91-8.

7. Kyle SD, Morgan K, Espie CA. Insomnia and health related quality of life. Sleep Med Rev. 2010; 14(1): 69-82.

8. Choi SH, Terrell JE, Pohl JM, Redman RW, Duffy SA. Factors associated with sleep quality among operating engineers. J Community Health. 2013; 38(3): 597-602.

9. Araújo MFM, Lima ACS, Araújo TM, Veras VS, Zanetti MI, Damasceno MMC. Association of sociodemographic factors and sleep quality in Brazilian university students. Texto \& Contexto Enfermagem. 2014; 23(1): 176-84.

10. Knudsen HK, Ducharme LJ, Roman PM. Job stress and poor sleep quality: data from an American sample of full-time workers. Soc Sci Med. 2007; 64(10): 1997-2007.

11. Metlaine A. Socioeconomic impact of Insomnia in working populations. Ind Health. 2005; 43(1): 11-19.

12. Soltani M, Haytabakhsh MR, Najman JM, Williams GM, O'Callaghan MJ, Bor W, et al. A sleepless nights: the effect of socioeconomic status, physical activity, and lifestyle factors on sleep quality in a large cohort of Australian women. Arch Womens Ment Health. 2012; 15(4): 237-47.

13. Sallinen M, Kecklund G. Shift work, sleep, and sleepiness-differences between shift schedules and systems. Scand J Work Environ Health. 2010; 36(2): 121-33.

14. Magnavita N, Garbarino S. Sleep, health and wellness at work: a scoping review. Int J Environ Res Public Health. 2017; 14(11): 1-18.

15. Lombardi DA, Folkard S, Willetts JL, Smith GS. Daily sleep, weekly working hours, and risk of work-related injury: US National Health Interview Survey (2004-2008). Chronobiol Int. 2010; 27(5): 1013-30.

16. Uehli K, Miedinger D, Bingisser R, Durr S, Holsboer-Trachsler E, Maier S, et al. Sleep quality and the risk of work injury: a Swiss case-control study. J Sleep Res. 2014; 23(5): 545-53.

17. Rakim W, Taboonpong S, Chailungka P, Juthong S. Sleep quality, factors interfering with sleep, and intervention activities among patients receiving mechanical ventilation. Songkla Med J. 2006; 24(4): 289-98.

18. Chaiarj S, Tachaudomdach J, Boonchuang P, Srisuphan S. Sleep quality and factors interfering with sleep among hospitalized patients in Medical Units. Thai Journal of Nursing Council. 2007; 22(4): 50-63.

19. Yamma C, Lueboonthavatchai P. Sleep problems, fatigue and work efficiency among Registered nurse at King Chulalongkorn Memorial hospital. J Psychiatr Assoc Thailand. 2013; 58(2): 183-96.

20. Chaiard J, Deeluea J, Suksatit B, Songkham W, Inta N. Short sleep duration among Thai nurses: influences on fatigue, daytime sleepiness, and occupational errors. Journal of Occupational Health. 2018; 60(5): 348-55. 
JHR

33,2

21. Boonyagate K, Taneepanichskul N. Effect of sleep quality on blood pressure and heart rate among shift nurses in a public hospital in Bangkok, Thailand. J Health Res. 2017; 31(S1): S51-6.

22. Chawnafang C. Sleep affecting errors in work of employees at the Concrete Products and Aggregate Co., Ltd (CPAC). Industrial and Organizational Psychology Thesis, King Mongkut's University of Technology North Bangkok; 2009.

23. Sitasuwan T, Bussaratid S, Rattanaumpawan P, Chotinaiwattarakul W. Reliability and validity of the Thai version of the Pittsburgh sleep quality index. J Med Assoc Thai. 2014; 97(S3): S57-67.

24. Buysse DJ, Reynolds CF 3rd, Monk TH, Berman SR, Kupfer DJ. The Pittsburgh Sleep Quality Index: a new instrument for psychiatric practice and research. Psychiatry Res. 1989; 28(2): 193-213.

25. Walsh JK. Clinical and socioeconomic correlates of insomnia. J Clin Psychiatry. 2004; 65(S8): 13-19.

26. Hartwell EE, Bujarski S, Glasner-Edwards S, Ray LA. The association of alcohol severity and sleep quality in problem drinkers. Alcohol and Alcohol. 2015; 50(5): 536-41.

27. Janson C. Insomnia in men-a 10-year prospective population based study. Sleep. 2001; 24(4): p. 425.

28. Sabanayagam C, Shankar A. The association between active smoking, smokeless tobacco, secondhand smoke exposure and insufficient sleep. Sleep Med. 2011; 12(1): 7-11.

29. Mak KK, Ho SY, Thomas GN, Lo WS, Cheuk DK, Lai YK, et al. Smoking and sleep disorders in Chinese adolescents. Sleep Med. 2010; 11(3): 268-73.

30. Krishnan V, Dixon-Williams S, Thornton JD. Where there is smoke...there is sleep apnea. Chest. 2014; 146(6): 1673-80.

31. Hamilton NA, Pressman M, Lillis T, Atchley R, Karlson C, Stevens N. Evaluating evidence for the role of sleep in fibromyalgia: a test of the sleep and pain diathesis model. Cogn Ther Res. 2012; 36(6): 806-14.

32. Stanos S. Focused review of interdisciplinary pain rehabilitation programs for chronic pain management. Curr Pain Headache Rep. 2012; 16(2): 147-52.

33. Doufas AG, Panagiotou OA, Ioannidis JP. Concordance of sleep and pain outcomes of diverse interventions: an umbrella review. PLoS One. 2012; 7(7): p. e40891.

34. Finan PH, Goodin BR, Smith MT. The association of sleep and pain: an update and a path forward. J Pain. 2013; 14(12): 1539-52.

35. Boivin DB, Boudreau P. Impacts of shift work on sleep and circadian rhythms. Pathologie Biologie. 2014; 62(5): 292-301.

Corresponding author

Jindarat Chaiard can be contacted at: jindarat.c@cmu.ac.th

For instructions on how to order reprints of this article, please visit our website:

www.emeraldgrouppublishing.com/licensing/reprints.htm

Or contact us for further details: permissions@emeraldinsight.com 